\title{
Peculiarities of mentality reflection through tense-aspect verb forms in Russian and English languages
}

\author{
Vladimir I. Bolotov - Ekaterina A. Samorodova - Elena S. Zakirova - Irina \\ G. Belyaeva
}

DOI: 10.18355/XL.2021.14.02.07

\begin{abstract}
In this article, we are trying to analyze the connection between Mentality and TenseAspect Verb Forms both in Russian and English Languages. The main task of our research is to reveal analytically what this or that form of the verb means in English and what meaning can the similar verb form be understood in Russian. The results of this study in the form of recommendations for achieving maximum pragmatic effect in the translation of English and Russian texts can be a good help for interpreters. Moreover, analyzing language through the prism of mentalities allows us to gain a deeper understanding of linguistic phenomena and develop a strategy to facilitate the process of learning English. The purpose of this study is to analyze the nature of verb as the most difficult section of the grammar from the perspective of reflecting the mentality in its grammatical forms and semantic meanings both in Russian and in English to create a list of recommendations that contribute to the correct understanding of English texts and their adequate translation.
\end{abstract}

Key words: mentality, English, verb, learning, nature of verb, tense-aspect verb forms

\section{Introduction}

The relationship between mentality and language is complex and ambiguous. As a language is formed under the influence of the mentality of a nation, so the mentality of a nation is formed under the influence of language. We consider the peculiarities of people mentality can be mostly manifested in the lexical units of their native language since the reality is mainly reflected in the names of objects around people.

The vocabulary of a language is influenced by national culture, people's living standards, customs and traditions, and many other factors. The nation mentality, the way of people's thinking are likely to be influenced by the grammatical and lexical structure of the language. Typically, the relationship between people's thinking process and the construction of phrases and sentences is based on certain grammar rules of the language being used in communication.

It should be noted that a person normally composes his or her speech not only on the basis of grammatical structures of the language but choosing the right lexical units (different parts of speech) reflecting more exactly the language picture of the world. The idea of the existence of the language worldview was firstly expressed by Humboldt in his book ( Humboldt,1985) who wrote "Languages are different national bodies for their original thinking and perception" being influenced by a number of cultural, political, social, and other reasons (Humboldt,1985).

Lexical content includes not only nouns as well as different parts of speech. Many researchers have turned to the study of language and mentality, for example (ZHeleznyak, 2008), (Fetzer, 2001), ( Merkish, 2020).

In this article, we are trying to analyze the connection between Mentality and Tense-Aspect Verb Forms both in Russian and English Languages. The main task of our research is to reveal analytically what this or that form of the verb means in English and what meaning can the similar verb form be understood in Russian. 
The results of this study in the form of recommendations for achieving the maximum pragmatic effect in the translation of English and Russian texts can be a good help for interpreters. Moreover, analyzing language through the prism of mentalities allows us to gain a deeper understanding of linguistic phenomena and develop a strategy to facilitate the process of learning English.

The purpose of this study is to analyze the nature of verb as the most difficult section of the grammar from the perspective of reflecting the mentality in its grammatical forms and semantic meanings both in Russian and in English to create a list of recommendations that contribute to the correct understanding of English texts and their adequate translation.

We consider the system of tense-aspect verb forms in English and Russian languages to be different. The Tense is the grammatical category which means when (what time) the action is taking place. The Aspect is the grammatical category which means "how" (in what way) the action taking place. The concept of "how" characterizes an action in general and is different in its meaning in Russian and in English. In Russian, the "aspect" is limited to one verb and expressed by different affixes, and the English form is not limited to one verb and can be expressed by different verbs, relative tenses, compound phrasal and nominal verbs, which, as we believe, refer to the perfect Aspect, e.g. nuсать, написать, записать can be translated into English by the word write. Nevertheless, nepenucamb is translated into English as copy, вbinucamb as write out etc. (see Rosemary). The compound verbal phrase I am writing indicates not only the duration of the action at a certain moment but also the length of time: the Russian verb can indicate the present, past or future Tense in one verb. Therefore, I am writing now, I was writing at 5 p.m. yesterday, I will be writing at 5 p.m. tomorrow are translated by the Russian verb nuсать: я пишу, $я$ писал, я напишу. It means that the verb in Simple tense write v. can completely replace the compound verbal phrases identified as Relative Tenses.

We differ the imperfect Aspect of verb and the perfect Aspect of verb on the basis of the following principle. The imperfect Aspect of verb is a general term for simple, complex, and derived verbs. The perfect Aspect of verb cover phrasal and compound nominal verbs.

We distinguish the Absolute System of Tenses including Present Indefinite (Simple) Tense, Past Indefinite (Simple) Tense, Future Indefinite (Simple) Tense and the Relative System of Tenses including Present Continuous (Progressive) Tense, Past Continuous (Progressive) Tense, Future Continuous (Progressive) Tense, Present Perfect Tense, Past Perfect Tense, Future Perfect Tense, Present Perfect-Continuous Tense, Past Perfect-Continuous Tense, Future Perfect-Continuous Tense.

In this research, we have revealed that compound phrases express an action in a perfect form occurring in a small period of time (as usual or long action either in the present, in the past, or in the future). Moreover, in the Absolute System of Tenses, the verbs can replace the other verb phrases, not changing their meaning and conveying the perfect form.

\section{Materials and Methods}

This work is highly synchronous research. We consider the modern language to be more or less constant at this period regardless of its old forms and meanings. We are considering the relations between modern linguistic signs from the point of view of their current state, occasionally referring to the facts of the history of the language in order to predict the development of the language in the future.

To solve our research goal, it is necessary to analyze the concept of mentality firstly as a way of thinking and the verb as a unit of speech as well as their relationship including the way of its expression both in Russian and in English.

XLinguae, Volume 14 Issue 2, April 2021, ISSN 1337-8384, eISSN 2453-711X 
The different understanding of mentality (Pinker, 2007), and its definitions can be found in scientific works ( Kolesov, 2006 ), (Bolotov, Zakirova, Karabucshenko, 2019), and others.

Thus, this study will focus on the peculiarities of the verb functioning both in English and in Russian languages, particularly on the features of these peoples mentality reflection through verb as a language unit. (ltenbach,2020) let us to compare the main features of Russian and English verbs, taking into account such its categories as Tense, grammatical Aspect, grammatical person, number, mood, voice, semantics as well as the peculiarities of Russian and British mentality reflection in these grammatical categories. It should be noted that for analysis of the examples have mostly been used the R. Courtney Longman Dictionary of Phrasal Verbs. The special edition (Courtney, 1986).

In this research work, such methods as analysis, synthesis, modeling, classification, deduction, induction, analogy, and abstraction have been used.

\section{Research results}

Relationship of Categories of Tense and Aspect in English and Russian Languages

The relationship between Categories of Tense and Aspect in a language can be explained as if we compare the existence of matter in Cosmos as a set of physical entities, but the categories of time and space can be considered as the conditions for their existence. The existence of a philosophical category of time is similar for all languages: it can be used for the description of present, past, and future events and actions.

The category of Aspect in a language indicates time of action as well as a predicate group in speech, which characterizes the Subject in a sentence giving it a permanent attribute with an adjective, and a variable attribute with a predicate, which in its turn can be characterized by an object and different types of adverbial modifier.

Therefore, there are many aspects to a language. A speaker understands, describes, identifies them in different languages and he or she is able to translate them from one language to another. At the same time, the mentality of this or that nation plays an important role in understanding and translation.

The categories of tense and Aspect are closely interchanged in speech, giving it various semantic and contextual meanings. The category of Aspect is traditionally understood in English as the syntactic category of speech. Previously, it was believed that it could be created only by fixed verbal phrases expressed by such complex tenses as Continuous Tenses, Perfect Tenses, Perfect Continuous Tenses, which accordingly denote the duration of an action at a certain moment, a complete action by a certain moment, a long action before (and possibly after) a certain moment.

Nowadays, the perfect Tense loses its specific meaning. It should be noted that such adverbs as already, this month, just, ever, yet can be used in the sentences with Predicate in the Simple Tenses, e.g.: 1) Several projects already launched deserved further attention. 2) Well, she obviously already told you about it. 3) I'm already listed in several bio-mechanical texts, Doctor! 4) Steel production will increase $2 \%$ this month from last month. 5) No VRS weapons storage sites were closed this month. 6) We were just awarded \$25 million. 7) And no-one who ever goes to live there ever seems to come out. 8) At least I did something right today. 9) The cheese that came off the boat today was delivered here today. [https://context.reverso.net].

It can be found in the Complex Tenses (Continuous Tenses, Perfect Tenses, Perfect Continuous Tenses), e.g.: 1) It's exhilarating yet ultimately destructive. 2) But we weren't talking business yet. 3) Certain issues are already being pursued, and the Secretary-General will be kept informed. 4) United Nations funds and programmes operating in the field are already responding. 5) You're already wearing more pain cream than clothes. 6) And the wider problems of the fragile situation were tragically 
illustrated today. 7). Because I saw her Range Rover driving down San Vicente today. [https://context.reverso.net].

It should be noted that in sentences with the Complex Tenses not the whole action in the present, past and future can be indicated, but part of it, some of its segments: this or that action can be continued in the future, e.g.:

1) In the phrase "I have written a letter today" the period of time is limited by the word "today".

2) In Perfect Continuous Tense, not the whole action is indicated, but only its continuous part, which can be prolonged later, i.e. after "today".

Actually, in the Perfect Tense the action is potentially characterized as being lasted one for a long segment of the previous time, but we have the opportunity to extend it until the end of a certain moment of the subsequent time. Therefore, the phrase "I have written a letter today" can be understood as "I wrote a letter today, but I can continue to write it until the end of the day, until the end of "today."

Typically, the Perfect Continuous Tense means that the action is characterized by a definite duration for a specific period of time, which can continue further, e.g. "I have been writing a letter for two hours". Having relied on the System of Verb Tense Forms in English language we suppose that for English people, the Complex Tenses (Continuous Tenses, Perfect Tenses, Perfect Continuous Tenses) denote a specific period of time during which an action can last. Thus, it means that an action can start before the moment of speech, last at the moment of speech, and end some time after it. In the Russian language, the given phrase can be represented as "Я пишу письмо два yaca". Therefore, the absence of a similar System of Verb Tense Forms in Russian language can be compensated by means of an object or by different types of adverbial modifier, i.e. the lexical environment in the Russian sentence being connected with the Predicate. For example, in the sentence I go to the room, the action is indicated only with the help of the Present Tense. In the sentence, I quickly go to the room, in addition to indicating the action, there is also an indication of the nature of the action (time and Aspect) in the Present Tense. This is a perfect aspect, but not of a verb, but a predicate group in speech.

In the Russian language, the grammatical category of Aspect is considered to be a morphological category of speech. Due to the widely developed affixal system in Russian, the form of the verb can be expressed by means of changing the affixes (with the same root) or by means of adding the affixes to the verb root, e.g. бежать, прибежать, забежать: these verbs can be translated by English verb run.

The Russian verb бездельничать being of imperfective aspect covers in its synonymous chain such verbs as побездельничать being of perfective Aspect as well as пробездельничать being of perfective Aspect but both of these verbs are translated by English verb - idle. Thus, both perfective Aspect and imperfective Aspect of Russian verbs are formed at the morphological level. Actually, perfective Aspect and imperfective Aspect of English verbs are expressed in several ways:

1) At the lexical level of the language, when comparing synonyms. It should be noted that simple verbs consisting of one word, derivative verbs, and compound verbs can be determined as imperfective verbs, while prepositional verbs are normally determined as perfective verbs, e.g. be readv for, fall in, look at, put on, take off. In the speech, these shades of meaning can be expressed by adverbs or synonyms.

2) The authors' point of view that category of Aspect in Russian is expressed morphologically within the form of the verb, and in English it is determined syntactically by means of a predicate, i.e. its tense form is far from ideal with respect to the English language.

Traditionally, before the twentieth century, the category of Aspect in English is manifested mainly in speech, although it can potentially exist in the language. It should

XLinguae, Volume 14 Issue 2, April 2021, ISSN 1337-8384, eISSN 2453-711X 
be noted that the category of Aspect differs in both Russian and English languages. In speech, it gives the same verb form, either imperfective Aspect or perfective one depending on the lexical environment.

In Russian, the category of Aspect can define an action as a short-term or complete one, as opposed to usual or perpetual action. Moreover, the category of Aspect can be perfective, e.g. бежать or imperfective one, e.g. побежать being created by the affix. The above-mentioned examples support the idea that the perfective Aspect of the verb is semantically marked by temporal meaning. It is explicitly determined in Continuous Tenses and implicitly in Perfect Tenses.

An imperfective aspect of the verb is an unmarked category, an abstraction that conveys the general concept of the verb (hyperonym). The Indefinite (Simple) Tenses are unmarked categories since they express only temporal meaning. Normally, the verbs of Indefinite (Simple) Tenses do not have any aspect form: it can arise due to using the definite adverb or other lexical units with temporal meaning.

The perfect form accompanies a specific, frequent verb with "subordinate" to the imperfective verb.

The difference between the aspect meaning in Russian and in English is that in the Russian language, the concept of an aspect combines words of a synonymic chain with the same root but different affixes. In English language, synonyms are combined, i.e. words with different roots, but with similar meanings.

\section{Features of the Tense Forms in the Russian and English Languages}

In a general sense, the concept "time" denotes a philosophical, physical, and everyday understanding of time for objects in the environment or human action in social life (the present, the past, and the future). The concept "tense" denotes an action in the present, past, and future expressed by the verb form in the function of Predicate in speech or text.

In the English language, the concept "tense" denotes the action in the present, past, and future expressed by the verb form, which does not coincide with the philosophical and ordinary concept' time' in its meaning as in the Russian language. Moreover, contrary Russian language in English Grammar there are 12 Active Voice Tenses and 8 Passive Voice Tenses. It should be noted that only the Simple (Indefinite) Tense coincides in its meaning with the philosophical and physical concept "time". The other English Verb Tenses include some additional specific characteristics of action which should be identified in situations of speech communication. The Indefinite Tenses can be considered as a language unit, unlike the Continuous Tenses, the Perfect Tenses, the Perfect Continuous Tense which can be considered as a speech unit.

The Absolute Tense is so named because:

1) it does not depend on other auxiliary members of the predicate group;

2) can replace all relative tenses without significant loss of meaning;

3) built on a synthetic model;

4) grammatical concept "tense" is equal to the philosophical and physical concept "time".

The Relative Tense is so named because:

1) it depends on other subordinate members of the predicate group in speech;

2) built on an analytical model;

3) grammatical concept "tense" is not equal to the philosophical and physical concept "time".

The English Verb Tenses include two different groups: the Absolute Simple Tense group and the Relative Tenses group, representing fixed phrases with the finite forms of the verb and non-finite forms of the verb.

The Absolute Tense System of verbs include Simple Tenses being so-called because of its synthetic structure, which consists of: 1) the word stem + ending 's' (3rd person singular e.g he works), 'es' (e.g stresses) in 
2) the word stem + ending 'ed' (e.g. washed) in the Past Simple Tense; for the Future Simple Tense we use "will" proposed stem for all persons, e.g. they will work, she will wash, etc. The action in Simple Tense can be identified as an indefinite one on the basis of the fact that it can potentially replace any fixed phrase in terms of duration and characteristic in a sentence without a loss of meaning.

The Relative verb phrases include three tenses indicating: a long action (the Continuous Tense), a complete action (the Perfect Tense), and a long-complete action (the Perfect Continuous Tense).

The Continuous Tenses denote an action lasting for a period of time with a definite beginning and end in the present, past, and future. The construction of a sentence is based on the model "to be + Participle I" where the stem is "be doing" and the duration of the action is known, e.g. I am reading the book now.

The construction of a sentence in the Perfect Tense is based on the model "to have + Participle II" where the stem is "have done", e.g. "I have written a letter today" which English people understand as "I wrote a letter today".

The concept of "present time" in philosophical meaning does not coincide with the linguistic one because the British way of thinking is considered to be individualistic. In the same sense, the Present Perfect Tense "belongs" to the "individual". The Present Perfect Tense potentially means two periods of time: the action took place in the past recently or in an unfinished period of time and affects the events taking place as well as the mood of the speaker. The action is limited by past time; it can potentially be followed by both the present and the future time. It is identified with such limited words as: today, this week, this month, recently, lately, just, e.g. "My wife has come today".

The Present Perfect Tense denotes the definite duration of the action and the mentalphysical state of the English speaker. The present time can be explained as his or her (individual's) lifetime. In accordance with the Russian mentality, the present time is defined as "the moment between the past and the future", this time is more abstract, and it can be explained as the essence belonging to the whole nation.

The Past Perfect Tense and the Future Perfect Tense indicate that the action happened before another action or a certain moment in the past or in the future, e.g. "I had already cooked when he came (or by 6 p.m.). I will have already cooked when he comes (or by 6 p.m.)".

The Perfect Continuous Tense indicates a specific, long-term action being lasted for a definite period of time which can be expressed with the prepositions for, since denoting the time of action before another action or a certain moment, e.g. "I have already been walking for 2 hours today", "I had already been walking for 2 hours today when he came yesterday".

In Russian language, there are 3 tenses for imperfective verbs: читаю, читал, буду читать and 2 tenses for perfective verbs: прочитал, прочту. In the Russian language, the philosophical - physical concept "tense" designates the time in nature and human social life. It is completely covered by grammatical linguistic tenses. be defined as:

In the Russian language, grammatical tenses identify a period of time that can

1) a period of time lasting from an indefinite moment in the past till the definite moment in the present;

2) a period of time lasting from the definite moment in present till an indefinite moment in future;

3) a period of time lasting from the definite moment in present till the infinity in the future.

XLinguae, Volume 14 Issue 2, April 2021, ISSN 1337-8384, eISSN 2453-711X 
Thus, when working with English texts, it is recommended to pay special attention to the Simple (Indefinite) Tense since it can practically replace the other relative tenses. It is possible to accept the following comparison of the English Verb Tenses, taking into account the hierarchical principle:

1) the Continuous Tenses is the communicative (speech) unit;

2) the Perfect Tenses denotes a common action, intimate-personal conversation, typical British frequent communication;

3) the Perfect Continuous Tenses denotes typically British scientific and technical sophisticated rare communication.

\section{The features of the category of Tense in Russian and English languages}

Traditionally, the forms of the category of the tense characterize the action in a definite period of time. Usually, the grammatical category of the Tense in English language includes the following opposition: the Continuous Tense verb forms and the Non-Continuous verb forms. From our point of view, such opposition of Tenses is not correct. We consider that such opposition as the Absolute Tense System, expressed by the Simple Tenses, and the Relative Tense System, expressed by the Continuous Tenses, the Perfect Tenses, and the Perfect Continuous Tenses can be identified in the English language. They can be contrasted in accordance with their forms and meanings. Let us take a more detailed view of this opposition.

The verb form of Simple Tenses comprising the Absolute Tense System has a synthetic ending (-s, -es, -ed) in its structure. The verb form of the Relative Tenses System has an analytic structure including fixed grammatical word combinations of Finite Verb Forms as well as Non-finite Verb Forms (Infinitive, Gerund, Participle).

The category of "aspect" correlates to the predicative forms of the verb, as well as the Infinitive of the verb. In other words, the category of "aspect" in the English language is not the same as in the Russian language. In the English language, the "aspect" as a grammatical category is manifested in the predicate group due to Adverbial Modifies expressed by the prepositions or nouns with a preposition. They additionally characterize the verb, which in its turn characterizes the Noun in the function of the Subject. Traditionally, the category of "aspect" in the English language was considered to be a lexico-syntactic category of the predicate group.

In modern English, the meaning of "aspect" does not coincide with the meaning of "aspect" in Russian. In the English language, the "imperfect aspect" is a general abstract category, while the "perfect aspect" is a definite individual category in speech.

The Indefinite (Simple) Tense is much wider in its meaning than the Continuous Tense. The Indefinite (Simple) completely covers the Relative Tenses, e.g. "I am writing a letter = I write a letter now. // I have been writing a letter for two hours $=I$ write a letter for two hours". Although grammatically, the Indefinite Tense is wrong in these examples, the sentences are semantically clear. We suppose that the Relative Tenses play a purely stylistic role, and they can be changed by Absolute Tenses, i.e. the Indefinite (Simple) Tense.

We have tried to show that the category of "aspect" in the English language is manifested by grammatically fixed verbal phrases being used for colloquial English, which express significant segments of a long speech that are important for communication and happened before a certain moment in the present, past and future time.

In the Russian language, the imperfective verbs do not indicate the completeness of the action. It should be noted that the end or result of the action is indicated by the perfective verbs. The same verb form can express the meaning either in perfect Aspect or imperfect Aspect, e.g. nuсать, написать. 
The categories of "aspect" in English and Russian are different in their forms and meanings. In English, the same verb is used to express ongoing and completed actions, but in different grammatical forms, e.g. they write, they wrote, they have written. Nowadays, the category of "aspect" is not limited by different grammatical forms, it can be expressed by Adverbial Modifies of time, e.g. they wrote today.

Traditionally, in terms of the structure, the English verbs are divided into simple (to bake, to run), derivatives (to recharge, to mislead), compound (to proofread), phrasal (to turn out, to look for).

It can be assumed that simple, derivative, compound verbs have an imperfect form and denote only an abstract generic concept. As for phrasal and compound verbs, they convey a specific concept and denote a perfect action equal to a segment of the present, past or future but not the entire period of time.

This gives us the right to introduce the concept of "grammatical speech time", which is less than real: it is a long or ordinary segment of time always associated with a real event or real action, e.g. "The boy was sleeping when I came home".

The verb can denote an ordinary action that can always occur, sometimes, often, seldom, for a long or short time, i.e. the verb itself does not highlight this, and its Aspect depends on other members of the predicate group. Thus, the Aspect of the verb is not only the category of the verb in the language, but it is also the syntactic category of the predicate group in the sentence.

\section{Features of Grammatical and Lexical Meanings of Verbs in English and Russian Languages}

Traditionally, it is believed that the verb system of the English language includes the following groups according to their functions: 1) notional verbs, 2) linkverbs, 3) auxiliary verbs, 4) modal verbs. It is widely supposed that notional verbs can express full semantic meaning. We consider all above-mentioned types of verbs be semantically full ones, since they can express both the grammatical and lexical meanings.

Grammatical meaning is constant. Lexical meaning is variable: the notional verbs can be divided into specific verbs of action, e.g. run, open and abstract verbs of mental and physical state, e.g. be, have, think, feel, consider etc.

Mental-physical verbs have two types of lexical meanings. Firstly, abstract verbs that are close in their meaning to the existence of objects, e.g. to be, the possession of something, e.g. to have, the production of something, e.g. to do, etc. Typically they are called as copula verbs which have lost some of the specific lexical meanings (in this case, the meaning of the verb becomes more clear due to the words in the function of object or adverbial modifies). Secondly, (while preserving the lexical meaning), it is translated according to the dictionary meaning. In the modern English language, a verb is a morphological structure of a word.

The verb presents the verb form in Present Indefinite (Simple) Tense of the 1 st and 2nd persons singular, which consists of the verb stem, e.g. open, writ + ending 'e' (I /you open, I / you write). In the structure of the verb, the root, affixes, flection form the morphological unit, which means that plan of expression is irrelevant. Only the functions of the stem are relevant in speech and language. For example, the functions of the stem are: 1) the function of the 1st and 2nd person singular and the 1 st and 3rd person plural of the Present Indefinite (Simple) Tense, e.g. open v., write; 2) the function of the Infinitive without 'to' particle, e.g. open, write; 3) the function of the Imperative Mood, e.g. Open! Write! All the other Non-finite and Finite Forms of the verb are formed by means of inflectional affixes added to its stem.

The Present Simple Tense the first singular verb form, consists of the stem and the ending - e, e.g. I writ $+e=$ write.

XLinguae, Volume 14 Issue 2, April 2021, ISSN 1337-8384, eISSN 2453-711X 
The verb content plan has such categories as Tense, type, Aspect, person, number, voice, and mood. The Finite forms of the verb have these categories in the sentence are predicates.

The Non-Finite forms of the verb (the Infinitive, the Gerund, the Participle I, the Participle II) combine the properties of a verb and properties of a noun or an adjective / an adverb. In their meaning, the Infinitive and the Gerund are close to the Noun, and the Participles are close to the Adjective. In a sentence, the Infinitive and the Gerund have mainly the function of the Subject and the Object, and the Participles function as the Adjective. The main feature of Non-Finite forms of the verb is the inability to function as the Predicate.

Since the Old English period, the participles have retained their original meaning. The Present Participle (Participle I) is formed by means of -ing to the stem of the verb, e.g. open -opening, write - writing. The Present Participle (Participle I) denotes the Active Voice of the Present Tense, defining simultaneous with the Predicate tense (Participle I). The Past Participle (Participle II) is formed by means of ending - ed to the stem of the verb for regular verbs and for irregular verbs by changing the root (e.g. «written» is the third form). It denotes the passive voice (Participle II), e.g. open - (be) opened, write - (be) written. Therefore, a verb in this form (verb + ending) in a statement is a predicate form. The verb stem is an expression plan consisting of morphemes (the root, the affix). The verb stem with the Inflections makes the Formative Model. The content plan of the verb is its functions.

The verb stem performs the following functions in the language:

1) 1 st and 2 nd person singular in the Present Indefinite (Simple) Tense;

2) the 1 st, the $2 \mathrm{nd}$, and the $3 \mathrm{rd}$ person plural (the same tense), e.g. open;

3) the Infinitive, e.g. open;

4) the Imperative Mood, e.g. Open!

The verb stem is the basic unit in modern English. It doesn't have a meaning. This is the basic linguistic form of the verb, serving for the formation of the Finite and the Non-Finite Verb Forms by using the affixes. The categories of verbs are formed on the base of the verb stem (the Category of Tense, the Category of Person, the Category of Number, the Category of Voice, the Category of Mood).

The personal endings of the verb can combine several functions (the Person, the Number, the Mood, the Voice).

The Non-Finite Forms of the Verb are the Infinitive, the Gerund, the Participle I, the Participle II. They are used in the sentence as its members (the Subject, the Object, the Adverbial Modifiers) with the exception of the Predicate. The Infinitive and the Gerund, according to their structure, are types of the Verbal Noun. The Participles are the types of Verbal Adjectives. Thus, The Non-Finite Forms of the Verb cannot function as the Predicate in a sentence. A verbal lexeme is the basic lexical unit, the complex of all forms and meanings of the verb stem and endings (the Inflections).

When considering verb categories, their forms, and oppositions in modern English, we take as a basis the normative forms and normative meanings of the language units that make up the majority, not the minority of them. We neglect the minority of them, with the exception of the most common forms and units.

A compound nominal verb contains two types of combinations:

1. Normative verbal speech combinations that have common concepts between the Noun and the verb, e.g. A schoolboy is reading a book where the subject field " a schoolboy " includes the concepts of "read", "book" and the subject field ("read" as the verb and "book" as the object) includes such Subject as "schoolboy", i.e. in this sentence we see A boy is which means "there is a boy" where these two words are independent members of the sentence. The word $a$ boy is the Subject and is as the form of the verb to be is the core of the Predicate. When Participle I or Participle II (e.g. reading or read) follows the verbs be, have (in its forms), then they indicate that 
this phrase refers one of the Relative Tenses, and separately the verbs be, have denote mental-physical time.

2. The fixed linguistic nominal verbs recorded in the dictionaries, e.g. send someone up to the wall, roll with the punch, root someone to the ground, muster up courage, to defeat one's fears, etc. can be considered syntactically whole and semantically united. The R. Courtney Longman Dictionary of Phrasal Verbs, Special Edition clearly shows the modern development of the verbal system in modern English from analyticism to synthetism. Semantically, this is obvious. There are fixed compound verbs, e.g. have one's heart in one boots, lough at one's sleeve, move in, wash over, etc. Some notional verbs of action have both lexical and grammatical meanings. They are always carriers of Tense (present, past, and future). Lexical meanings are individual (they belong to one verb), and grammatical meanings are collective, i.e. general (they belong to a group of verbs) and are of a philosophical, physical, and grammatical nature, e.g. plan (the Present Tense), I immediately plan (the Present Tense), I open (the Present Tense), I write (the Present Tense). The verb in the Absolute Simple Tense, e.g. I planned (the Past Tense), I opened (the Past Tense), I wrote (the Past Tense), I will write (the Future Tense). In all these sentences, the verb is imperfect, abstract and indefinite.

In the sentence, I immediately plan the predicate group takes on a perfect aspect, i.e., complete single action. In the sentence, I can plan (the present Tense), the verb of the physical-mental state has only the full grammatical meaning of the Tense. It should be noted that some of the verbs retained the lexical meaning partially. The main meanings of the Predicate are conveyed by the Noun, the Infinitive, the Gerund, the Participle, the Adjective, the Numeral. Sometimes such verbs are called linking verbs, e.g. I feel angry.

Such a simplified approach to semantics is necessary for the implementation of lexical analysis of the members of the sentence to one part of speech and in syntactical analysis for the identification of the nature of the members of the sentence and their parts.

We believe that all verbs are exclusively semantic or notional ones, but they are divided into

1) specific action verbs (write v., cut $v$., cry v. etc.)

2) verbs of the physical-mental state (think $v$, feel $v$. etc.): they are considered to be semantic-insufficient, abstract ones, in which nouns, adjectives, participles acquire the main meaning.

\section{Conclusion}

Almost all simple, derived, complex verbs are language verbs, most of the imperfect Aspect in the Indefinite (Simple) Tenses.

Most phrasal and compound nominal verbs are colloquial speech verbs of the perfect Aspect.

The fixed verbal phrases in the function of Relative Tenses are special speech combinations of the perfect Aspect, since they denote a specific action, not in the present, past, or future, but only in separate segments of the present, past, and future Tense, making communication more specific and more closely related to other actions or certain moments of verbal communication.

Thus, in the XX and XXI centuries in the English language, the Category of Aspect also becomes the category of language, not only the category of speech (syntax) in the predicate group.

They have acquired a peculiar perfect aspect of fixed verbal phrases in the Relative Tenses. The Category of Aspect has become quite frequent in English 
vocabulary and morphology. It is advisable to put a hyphen between the verb and its nominal part.

We try to demonstrate by this explanation that the nominal part (the Noun, the Adjective, the Infinitive, the Gerund, the Participle I, the Participle II) has automatically transformed by its function into a morpheme, and the English language has become a little more synthetic in its grammatical order.

Historically, quite recently, the verbs of perfective Aspect have emerged. They have become compound nominal and phraseological verbs, and the category of Aspect has become a complex speech / linguistic formation, a category of a verb in a language, and a predicate in speech.

To reduce the gap between the authors' intention and the translator's perception, we propose an algorithm for a sentence analysis:

1. the identification of the Predicate and the Subject;

2. the identification of the main groups: a) the subject b) the Predicate; then, the identification of the secondary groups within the Subject and the Predicate: c) the groups of the object, d) the adverbial modifier, e) the attribute;

3. the identification of the members of the sentence;

4. the morphological analysis of the structure of the sentence members;

5. when analyzing it should be necessary to consider the finite form of the verb, indicating the tense and the person, as a predicate.

6. all the units of a simple sentence that detail the verb should be considered as the parts of the predicate group in the function of the object or adverbial modify;

7. the verbs be v., have, which have lost their lexical meaning, form the fixed grammatical phrases, with non-finite verb forms called Relative Tenses, which denote specific actions in the form of periods of time at a certain moment or before it (the Continuous Tenses, the Perfect Tenses, the Perfect Continuous Tenses.)

If we decompose the Relative Tenses into components, then we get the following, e.g.: I was writing a letter at 7 p.m. yesterday. I wrote a letter at 7 pm yesterday. In this sentence, the form of the verb to be was means the past state, the Participle I writing denotes a simultaneous long-term action with a predicate in active voice, that is, I was writing means I wrote. When analyzing the sentence I have written a letter today we find that have means to possess something, denotes a past action in the passive voice, i.e. I have written letter (a letter written by me) or I wrote a letter today.

8. The verb do in its homonic distant morpheme of the notional verb is used in the Present Simple Tense and in the Past Simple Tense to form the interrogative and negative sentences, e.g. Do you (Does he) open the window? No, I don't. No, he does not (doesn't). Did you open the window. Yes, I did. No I did not (didn't.)

Thus, the verbs of the physical-mental state (seminotional verbs) turned into the Predicate, and their nominal parts became the significant units of the predicate group.

\section{Bibliographic references}

BOLOTOV, V.I. - ZAKIROVA, E.S. - KARABUCSHENKO, N.B. 2019. Zhinkin Code: thoughts on the universal subject Code (CPC) by N. I. Zhinkin / V.I. BOLOTOV, V.I. - ZAKIROVA, E.S. - KARABUCSHENKO, N.B. 2019. Sovremennaya nauka: aktual'nye problemy teorii i praktiki. Seriya: gumanitarnye nauki.Nauchnye tekhnologii (Moskva) ISSN: 2223-2982, n. 3, 2019 p. 118-132

COURTNEY, R. 1986. Dictionary of Verbal Idioms. Longman Dictionary of Phrasal Verbs (Slovar' glagol'nyh idiom ) 1986, Russkij yazyk, Moskva, p. 734

FETZER, J.H. 2001. Language and Mentality. In: Computers and Cognition: Why Minds are not Machines. Studies in Cognitive Systems, vol 25. Springer, Dordrecht. https://doi.org/10.1007/978-94-010-0973-7_4 
HUMBOLDT,W. 1985. Language and philosophy of culture (Yazyk i filosofiya kul'tury). Progress, Moskva,1985, P.448

ITENBACH, H. 2020. Scientific Language - A Comparative Analysis of English, German and Russian. Technology and Language, 1(1), 1-5. https://doi.org/10.48417/technolang. 2020.01.01

KOLESOV,V. 2006 Russian mentality in language and text. (Russkaya mental'nost' v yazyke i tekste). Peterburgskoe Vostokovedenie.2006. https://royallib.com/book/kolesov_vladimir/russkaya_mentalnost_v_yazike_i_tekste.h tml

MERKISH, N. 2004. Comprehension of the cultural component of vocabulary as a precondition for successful communication with native speakers. Science for Education Today 2020, 10, 175-188. 10.15293/2658-6762.2004.11.

PINKER, S. 2007. The Language Instinct (1994/2007). New York, NY: Harper Perennial Modern Classics.

ZHELEZNYAK, A. 2008. Language as an indicator of ethnic mentality (YAzyk kak indikator etnicheskogo mentaliteta). Analitika kul'turologii, (10), 218-233.

Words: 7063

Characters: 43779 (24,32 standard pages)

Professor Vladimir I. Bolotov,

Doctor of Science

RUDN University

117198, Moskow, Ulitsa Miklukho-Maklaya,6

Russia

ORCID: https://orcid.org/0000-0002-0932-5974

vladbol1931@mail.ru

Assoc. Prof. Ekaterina A. Samorodova, PhD.

French Language Department

Moscow State Institute of International Relations (MGIMO University)

119454, Moscow, Prospekt Vernadskogo, 76

Russia

ORCID: https://orcid.org/0000-0002-0702-0253

samorodova.ekaterina.78@mail.ru

Professor Elena S. Zakirova, Doctor of Science

Department of Linguistics and Professional Communication in the Field of Humanitarian and Applied Sciences

Moscow State Linguistic University

119034, 38 Ostozhenka St. Moscow

Russia

ORCID: https://orcid.org/0000-0003-4015-2212

zes.64@mail.ru

Irina G. Belyaeva, $\mathrm{PhD}$.

German Language Department

Moscow State Institute of International Relations (MGIMO University)

119454, Moscow, Prospekt Vernadskogo, 76

Russia

ORCID: https://orcid.org/0000-0002-7083-3564

i.beliaeva@inno.mgimo.ru

XLinguae, Volume 14 Issue 2, April 2021, ISSN 1337-8384, eISSN 2453-711X 